\title{
The role of Force Health Protection in the Canadian Armed Forces' response to the COVID-19 pandemic
}

\author{
Heather McCuaig Edge ${ }^{1,2 \star}$, Samantha Carlucci', Diane Lu'
}

\begin{abstract}
Within the Canadian Armed Forces (CAF), public health is managed by the Directorate of Force Health Protection (DFHP), a branch of the Canadian Forces Health Services Group. Since the emergence of the novel coronavirus (SARS-CoV-19), DFHP has become heavily involved in health surveillance, outbreak monitoring, policy development, providing evidencebased guidance and advice, liaising with other national, provincial/territorial, municipal and international public health agencies, and ensuring environmental safety of CAF members. Some specific activities include supporting operations and deployments, amending policies and training and promoting hand hygiene, physical distancing and personal protective equipment use. In addition to taking measures to protect its members, CAF-Department of National Defence has contributed to Canada's national response to coronavirus disease 2019 (COVID-19). The DFHP will be developing training for allied health professionals to assist with contact tracing and follow-up, and will ensure adequate resources are in place to manage surge capacity for COVID-19. With these ongoing efforts, initiatives and lessons learned, DFHP is well placed to carry on with its mandate to protect and promote the health and well-being of CAF members and National Defence civilian employees, assisting Canadians and ensuring that CAF members are ready to serve their missions at home and abroad.
\end{abstract}

This work is licensed under a Creative Commons Attribution 4.0 International License.

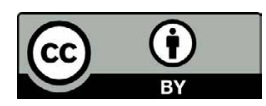

Affiliations

1 Directorate Force Health Protection, Canadian Forces Health Services, Ottawa, ON

${ }^{2}$ Directorate Research Personnel and Family Support, Department of National Defence, Ottawa, ON

\section{*Correspondence:}

heather.mccuaigedge@forces. gc.ca

Suggested citation: McCuaig Edge HJ, Carlucci S, Lu D. The role of Force Health Protection in the Canadian Armed Forces' response to the COVID-19 pandemic. Can Commun Dis Rep 2020;46(9):279-81.

https://doi.org/10.14745/ccdr.v46i09a05

Keywords: COVID-19, Directorate of Force Health Protection, Department of National Defence, pandemic response, coronavirus, surveillance, Canadian Armed Forces, public health, military

\section{Introduction}

In December 2019, a novel coronavirus emerged in Wuhan, China, causing an outbreak of the infectious disease, coronavirus disease 2019 (COVID-19), which has since become a widespread global pandemic (1). Public health agencies around the world and within Canada have been actively monitoring and responding to the needs of their respective jurisdictions. The responsibility of promoting public health within the Canadian Armed Forces (CAF) is managed and maintained by the Directorate of Force Health Protection (DFHP), a branch of the Canadian Forces Health Services Group.

\section{Role of Force Health Protection in the Canadian Armed Forces' response to coronavirus disease 2019}

DFHP is responsible for promoting the well-being of military members, and for epidemiological surveillance, communicable disease control and prevention, health promotion and occupational and environmental health. As such, during the COVID-19 outbreak, DFHP became heavily involved in health surveillance, outbreak monitoring, policy development, providing evidence-based guidance and advice, liaising with other national, provincial and territorial, municipal and international public health agencies, and ensuring the environmental safety of CAF members and Department of National Defence (DND) staff members. 
CAF is required to maintain operational readiness to respond to emergencies in times of need while protecting the health of its members and taking precautions to prevent the further spread of the virus that causes COVID-19 (2). Like all Canadian government departments, CAF and DND were impacted by the previously unprecedented global and national COVID-19 response enacted in March 2020 following the World Health Organization declaration of a pandemic. Some direct impacts of the COVID-19 pandemic on CAF are outlined as follows:

1. Increasing the monitoring and surveillance of CAF members working abroad, for those deployed on operations, and at home

2. Taking measures to adjust operations, such as delaying deployments, amending the number of personnel who are deployed, and modifying the length of deployments to ensure personnel are protected while continuing to perform critical tasks (3)

3. Promoting good hand hygiene and physical distancing whenever possible, and donning appropriate personal protective equipment (PPE)

4. Reducing contact by imposing a 14-day quarantine before and after deployments on operations, with the Royal Canadian Navy testing sequestered individuals prior to boarding the ship

5. Requiring personnel to disclose their potential exposure to COVID-19 and to seek medical care promptly if they develop flu-like symptoms within 14 days of travel or have come into contact with someone infected with COVID-19 (2)

6. Cancelling annual military exercises and postponing basic military training and educational training across multiple sites, including the Canadian Forces Leadership and Recruit School in St-Jean, Québec and schools at Canadian Forces Base in Borden, Ontario

In addition to taking measures to protect its members, CAF-DND has contributed to Canada's national response to COVID-19, including retrieving and housing repatriated Canadians from travel abroad at Canadian Forces Base Trenton and Operation LASER, which involves assisting with the care of elderly residents in Ontario and Québec long term care facilities, deploying Canadian Rangers to assist northern communities in Québec and Saskatchewan, and contributing to community-level activities to assist municipalities in managing the spread of COVID-19 (4). As part of Operation LASER, Dental Technicians are currently assisting civilian public health authorities with daily follow-up of asymptomatic civilian personnel who are self-monitoring and/ or self-isolating following a potential exposure to a COVID-19 positive case.

Many of the decisions, practices, and activities described above were influenced by the advice and direction from DFHP. Each section within DFHP has been heavily involved in and contributed to different aspects of CAF-DND COVID-19 response. The Epidemiology section has provided surveillance and monitoring of Regular and Reserve Force CAF members for COVID-19, especially given deployments to long term care facilities (within
Canada) and deployments abroad. This has been achieved with the Canadian Forces Health and Evaluations Reporting Outcomes system and the Disease and Injury Surveillance System. The health promotion branch, Strengthening the Forces, has been involved in promoting healthy lifestyle behaviours and providing clinical guidance including smoking cessation and examining the role of vitamin D in preventing COVID-19. The World Health Organization has identified tobacco smoking as a risk factor for COVID-19 (5) and smoking has been presumed to be associated with adverse disease prognosis (6). In response, Strengthening the Forces has partnered with dental and pharmacy, among other partners within Canadian Forces Health Services, to actively promote smoking cessation to reduce harm to smokers during the pandemic. Strengthening the Forces has also been involved in the implementation of a contact tracing surge capability for CAF members. The Occupational and Environmental Health section has been continuously monitoring the pandemic and adjusting measures to protect CAF members and DND employees accordingly. These control measures consist of providing advice and guidance on feasible and effective engineering controls (i.e. proper operation of building ventilation systems, safeguarding drinking water potability), administrative controls (i.e. personal hygiene measures) and on the use of PPE (i.e. fit testing, medical grade versus industrial respirators, N95 reprocessing and the use of expired respirators). In addition, Occupational and Environmental Health has been providing support to the planning and implementation of Operation GLOBE (repatriation of Canadian citizens from abroad at the start of the pandemic) and Operation LASER, advice for Business Resumption Planning and assistance to the Canadian Forces Intelligence Command to assist their medical intelligence team. The Communicable Disease Control Program has been providing guidance on CAF-specific public health measures and policies to clinicians regarding diagnosis and management of cases including outbreak management. The Communicable Disease Control Program has been involved in infection prevention and control, contact tracing, responding to cluster outbreaks and the development of educational material for healthcare providers and CAF members.

Given that the national response to the pandemic, and CAF members themselves, are dispersed across the country, DFHP has had to work closely with the national, provincial/territorial, and municipal civilian public health sectors to achieve accurate COVID-19 surveillance. Regular Force and Class B and C Reserve Force members typically obtain their health care through base/wing clinics. However, part-time Class A Reserve Force members primarily obtain their health care through the civilian sector and much of the COVID-19 testing for any CAF personnel early during the pandemic was conducted by civilian provincial laboratories. Clinical encounters with Canadian Forces Health Services clinics are captured by DFHP, with initiation of appropriate follow-up and contact tracing. However, surveillance and monitoring for all CAF personnel is complex because testing and contact tracing is intertwined between the military and civilian sectors (local/provincial public health authorities). 
Adding to this complexity are the regional differences among the bases/wings across CAF due to provincial/territorial differences in reporting confirmed cases, contact tracing, developing policies around public health measures, and declaring states of emergencies. DFHP has been tasked by the Deputy Surgeon General with developing a training program for allied health professionals to conduct contact tracing to respond to possible surge capacity and cluster outbreaks of COVID-19.

As the situation normalizes and people return to work, a top priority for DND is the health of its CAF personnel. The DFHP is: 1) actively engaged in providing advice to CAF leadership regarding business resumption activities, 2) will continue to follow the epidemiological situation and scientific evidence closely in order to help make evidence-based recommendations on public health preventive measures, and 3) will continue to provide guidance and revise policies as the situation evolves.

\section{Ensuring better emergency preparedness in the future}

Throughout this pandemic, DND has been made aware of operational limitations. Some of the ways that DFHP is exploring to ensure better emergency preparedness in the future are described as follows:

1. Increase staffing resources, including ensuring that there is a surplus of readily-deployable trained staff (e.g. Preventive Medicine Technicians)

2. Improve communication, collaboration, and coordination of efforts between the military and civilian sectors

3. Improve surveillance capacity

4. Manage resources (e.g. PPE) as well as expectations of senior leadership/Chain of Command

With adequate support to these ongoing efforts, initiatives, and lessons learned, DFHP is well placed to carry on with its mandate to protect and promote the health and well-being of CAF members, and to ensure that members are ready to serve on their missions, both at home and abroad.

\section{Authors' statement}

HJME, SC and DL were all involved in the conceptualization, drafting, and revising of the paper.

\section{Competing interests}

None.

\section{Acknowledgments}

The authors would like to thank the members of the Canadian Forces Health Services Group and the Directorate of Force Health Protection, members of the Canadian Armed Forces, and all of the civilian and military front-line workers for contributing to the pandemic response. A thank you as well to Col P Morissette, Cdr K Barnes, LCol S Blier, Dr. M Carew and Mr. T Bradshaw for reviewing this report.

\section{Funding}

This work was supported by the Department of National Defence, Canada.

\section{References}

1. World Health Organization. Q\&A on coronaviruses (COVID-19). Geneva (CH): WHO; 2020 (accessed 202005-08). https://www.who.int/emergencies/diseases/ novel-coronavirus-2019/question-and-answers-hub/q-adetail/q-a-coronaviruses

2. Government of Canada. Military response to COVID-19. Government of Canada; 2020 (accessed 2020-05-08). https://www.canada.ca/en/department-national-defence/ campaigns/covid-19-military-response.html?utm_ source=covid-campaign\&utm_medium=heading\&utm_ campaign $=$ covid19

3. National Defence. Changes to military operations in response to COVID-19. DND; 2020 (accessed 2020-05-08) https://www.canada.ca/en/department-national-defence/ services/operations/military-operations/covid-19.html

4. National Defence. Operation LASER. DND; 2020 (accessed 2020-05-08). https://www.canada.ca/en/ department-national-defence/services/operations/ military-operations/current-operations/laser.html

5. World Health Organization (Region Office for the Eastern Mediterranean). Tobacco Free initiative: Tobacco and waterpipe use increases the risk of COVID-19. Cairo (Egypt): WHO (accessed 2020-04). www.emro.who. int/tfi/know-the-truth/tobacco-and-waterpipe-user s-are-at-increased-risk-of-covid-19-infection.html

6. Vardavas Cl, Nikitara K. COVID-19 and smoking: A systematic review of the evidence. Tob Induc Dis 202018(March):20. DOI PubMed 